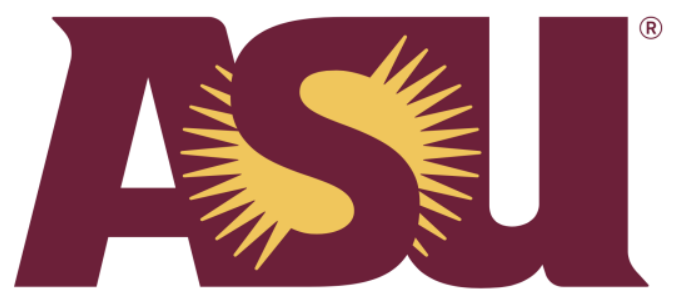

Center for

Global Health

Arizona State

University

Eyes on Our City

OBSERVATIONAL

PROTOCOL

2018 
Thank you for joining our "Eyes on the City" project. Citizen Social Scientists like you are key to doing great science. You bring fresh eyes and new observations.

Your student trainer is:

They can be contacted at:

\section{THE PROCEDURE}

1. Follow the map to the 9 locations in Downtown Tempe.

2. Record your Observations.

3. Take at least two photos of things that seem significant to you.

4. Return this booklet to your student-trainer.

Please record your birthdate:

Please record your primary phone number:

If you have any questions or concerns please call your student-trainer or project manager XXXX at 480-XXX-XXXX. 
LOCATION 1: Tempe Beach Park (1-49 W. Rio Salado parking lot)

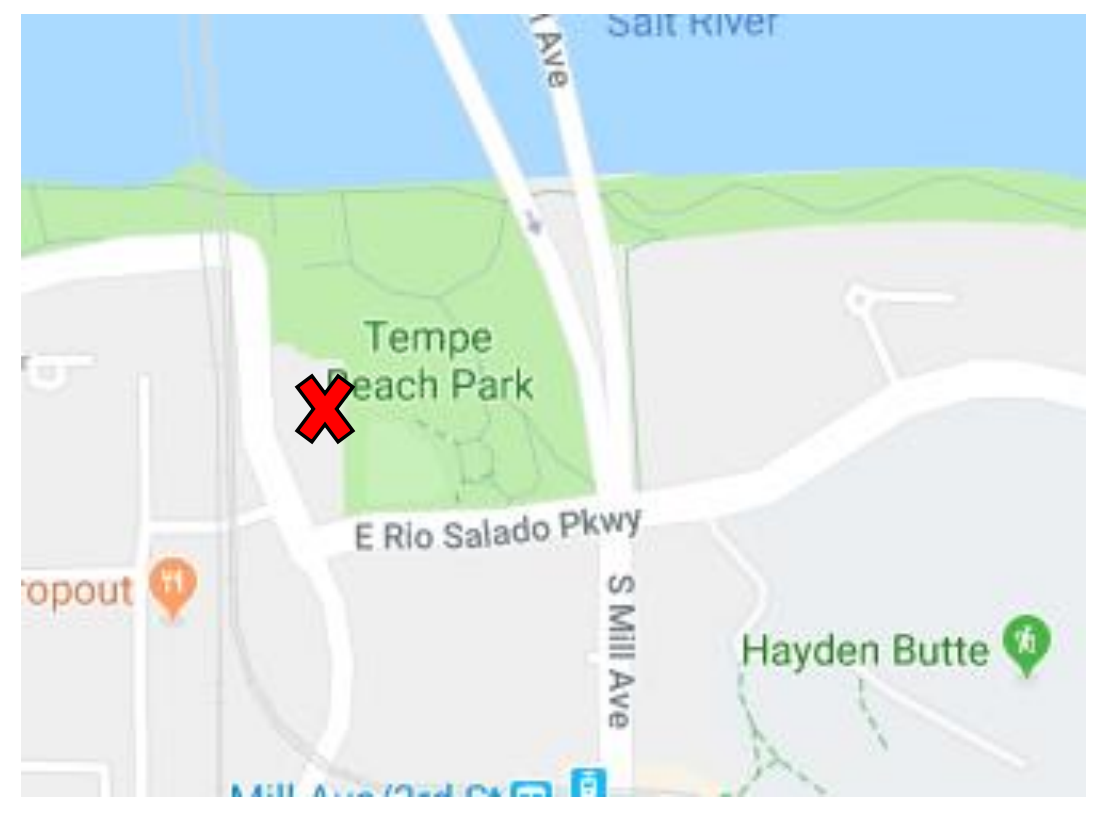

STARTING POINT: Facing east from the parking lot at 1-49 W. Rio Salado near the Blue Star Memorial plaque.

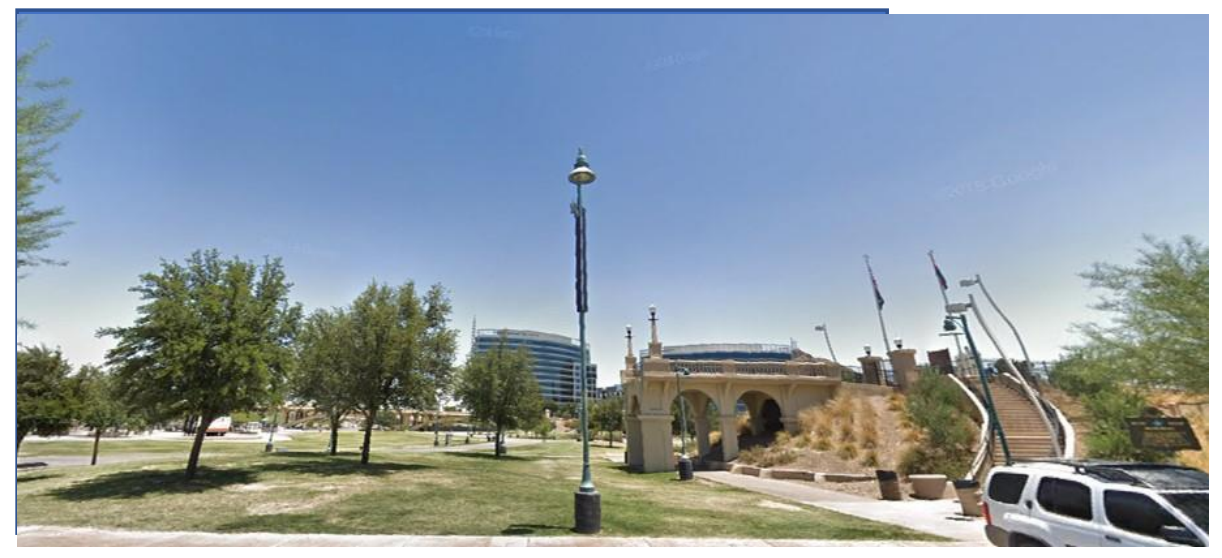

RECORDING INSTRUCTIONS: Walk up the West stairs. Then Walk down the East stairs. Walk to the paved area in the center of the park.

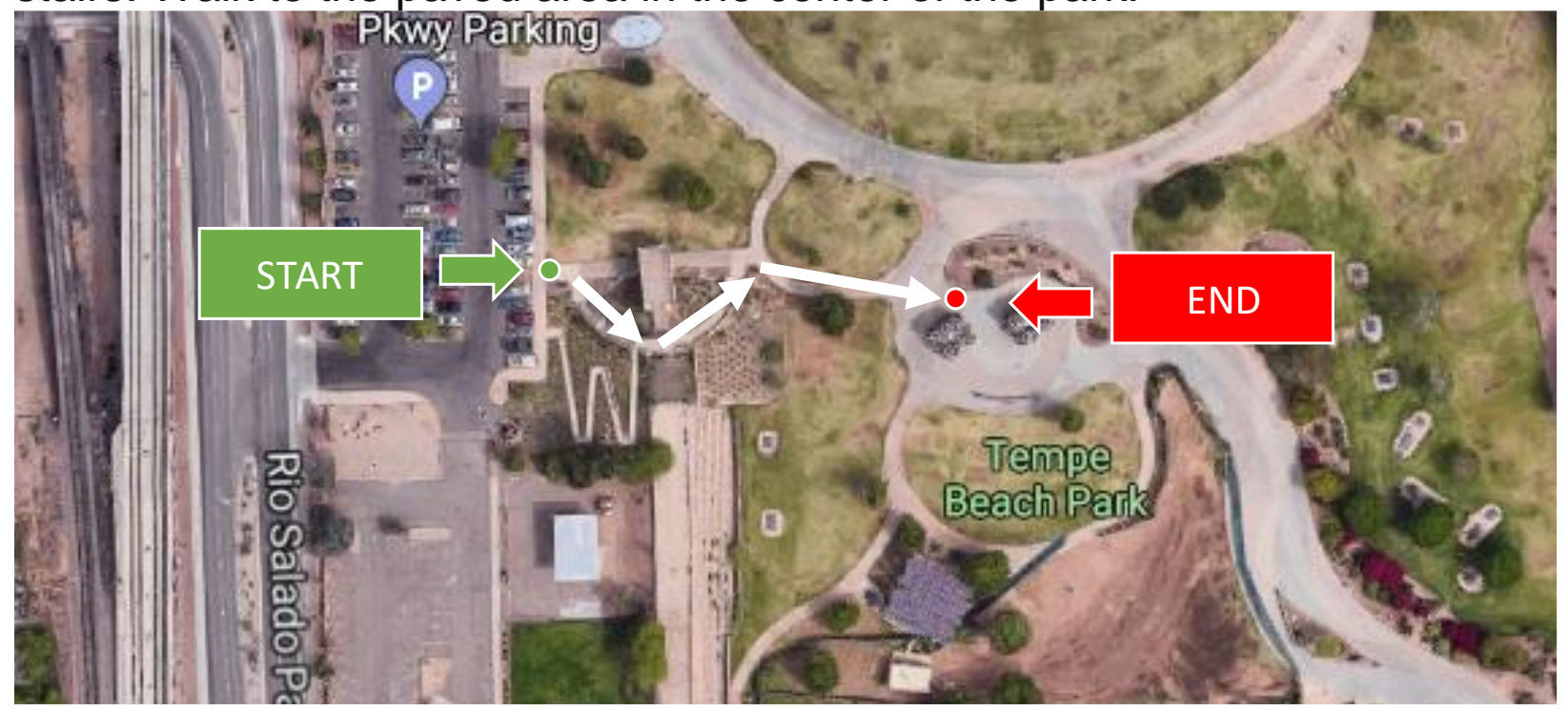


Remember: DO NOT include any notes about what people are doing in the spaces. Look just at fixed items in the environment, such as parts of buildings, equipment, and signs. Describe any items that you see in this location that could make any of the following groups feel unwelcome or excluded. Identify what you see, and tell us why you think it could be unwelcoming to any of the groups. Describe as many items as you can for each category. If there are no items relevant to that category, write "none".

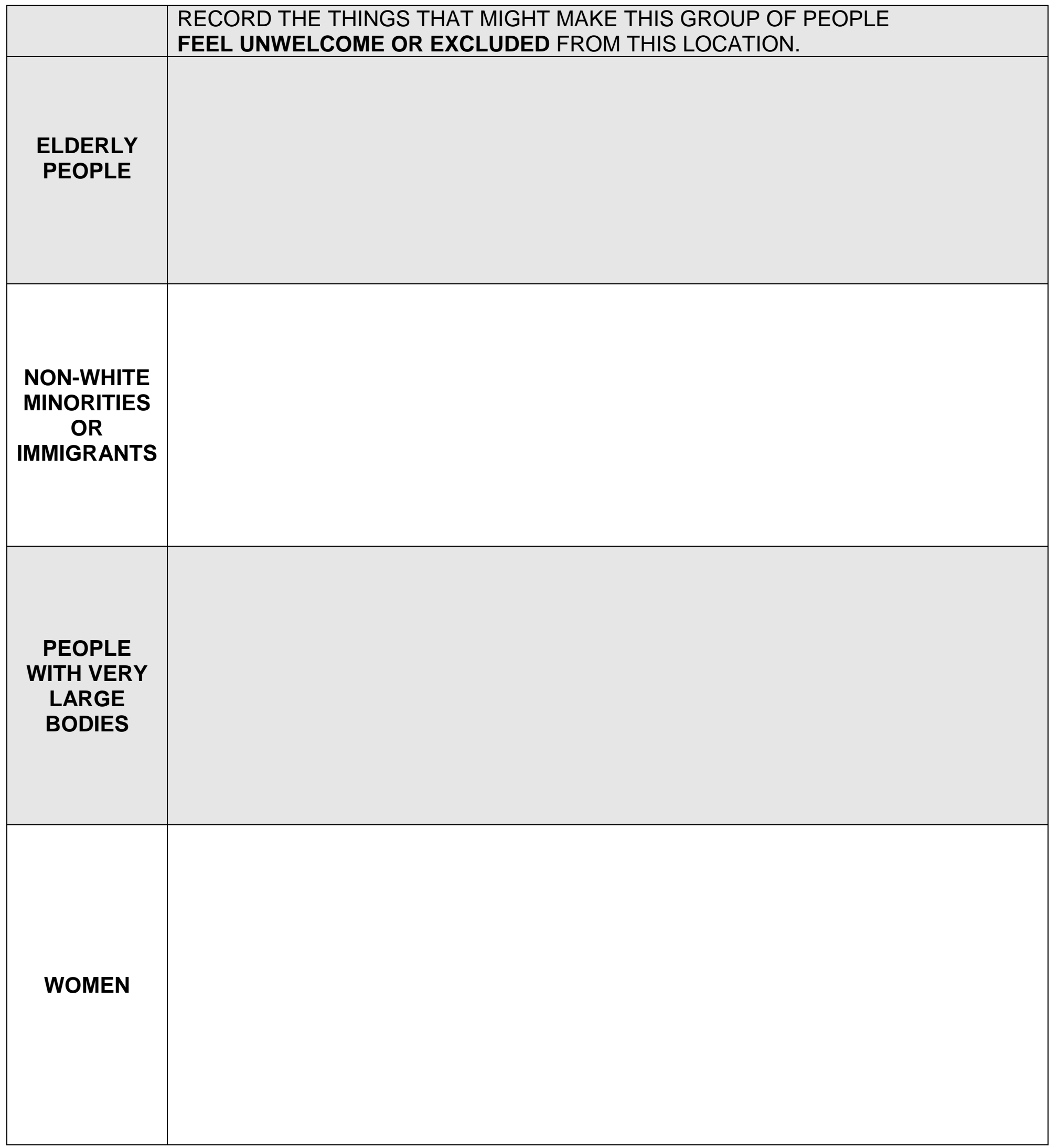




\section{LOCATION 2: Tempe Beach Park (Central, and North East part of park)}

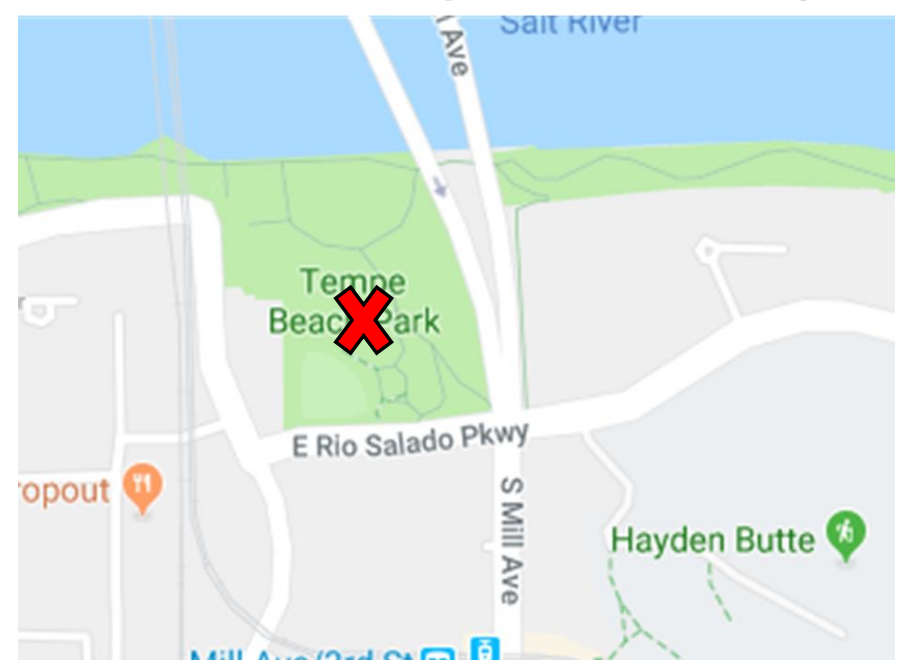

STARTING POINT: Paved area at center of Tempe Beach Park.

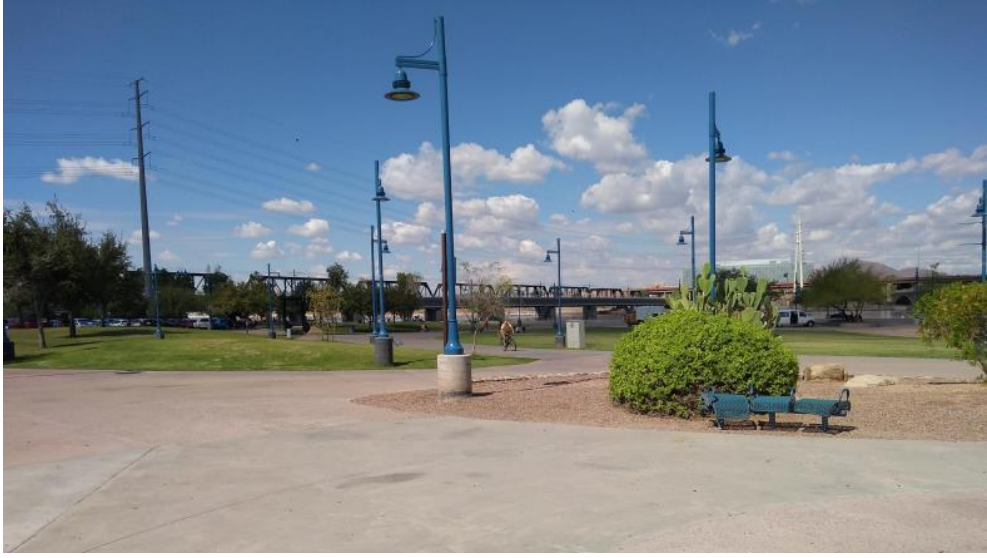

RECORDING INSTRUCTIONS: Walk North towards the canal to the West side of the boat rental station. Turn right and walk East along the canal and along the length of the boat rental station. Walk underneath the Mill Avenue bridge and stop. Turn right and walk along the Mill Avenue bridge into the green space at the South East corner of the park.

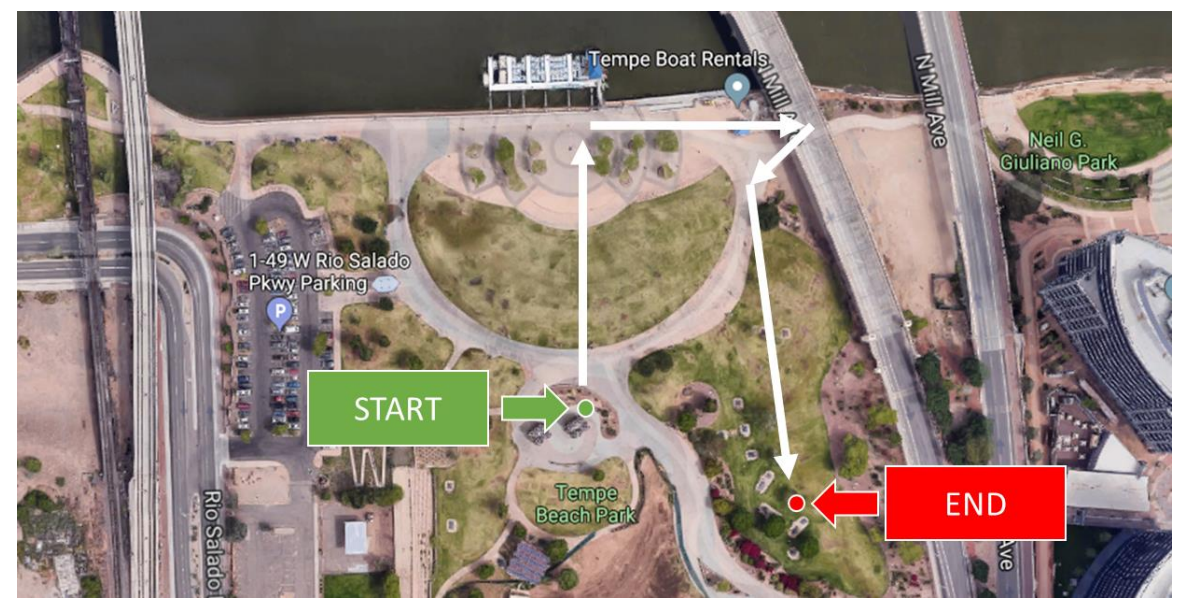


Remember: DO NOT include any notes about what people are doing in the spaces. Look just at fixed items in the environment, such as parts of buildings, equipment, and signs. Describe any items that you see in this location that could make any of the following groups feel unwelcome or excluded. Identify what you see, and tell us why you think it could be unwelcoming to any of the groups. Describe as many items as you can for each category. If there are no items relevant to that category, write "none".

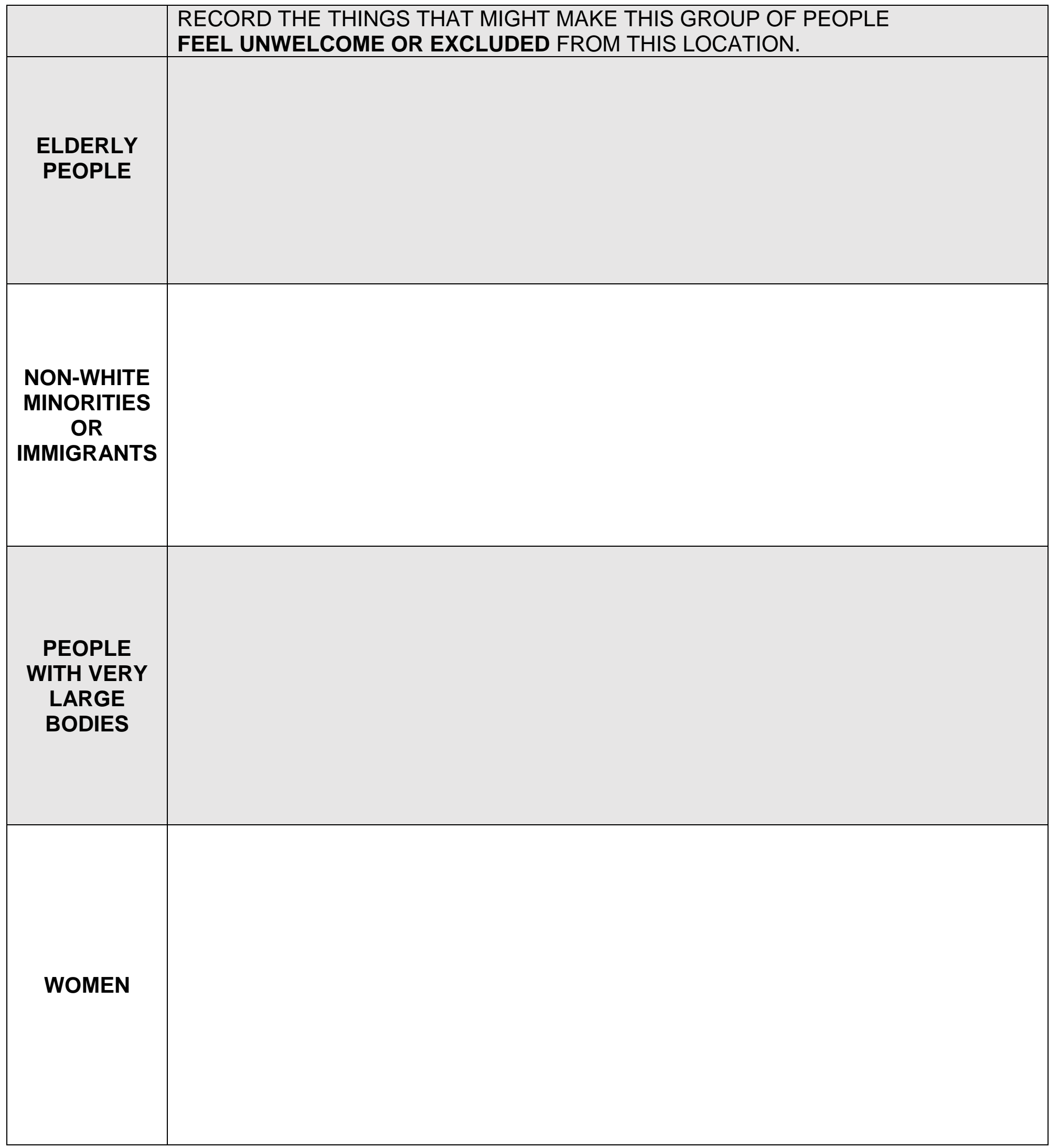




\section{LOCATION 3: Tempe Beach Park (South East area of Tempe Beach Park)}

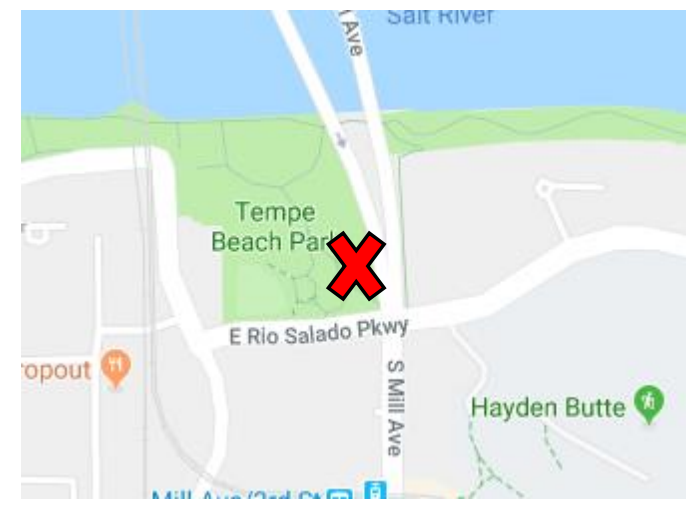

STARTING POINT: Base of the ramp near the South East entrance of Tempe Beach Park

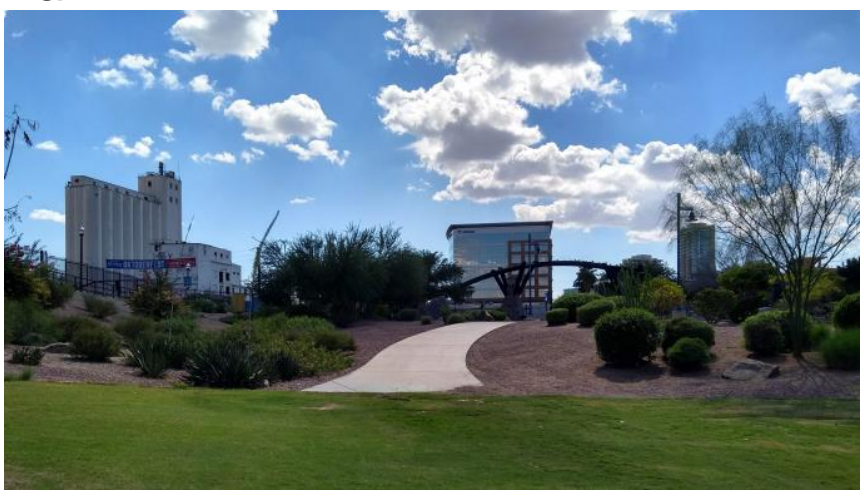

RECORDING INSTRUCTIONS: Walk South up the ramp towards the entrance to Tempe Beach Park. At the top of the ramp at the main walkway turn right and walk North West. Turn left and walk to the bathrooms. Turn around walk back to the main walkway and then exit the park.

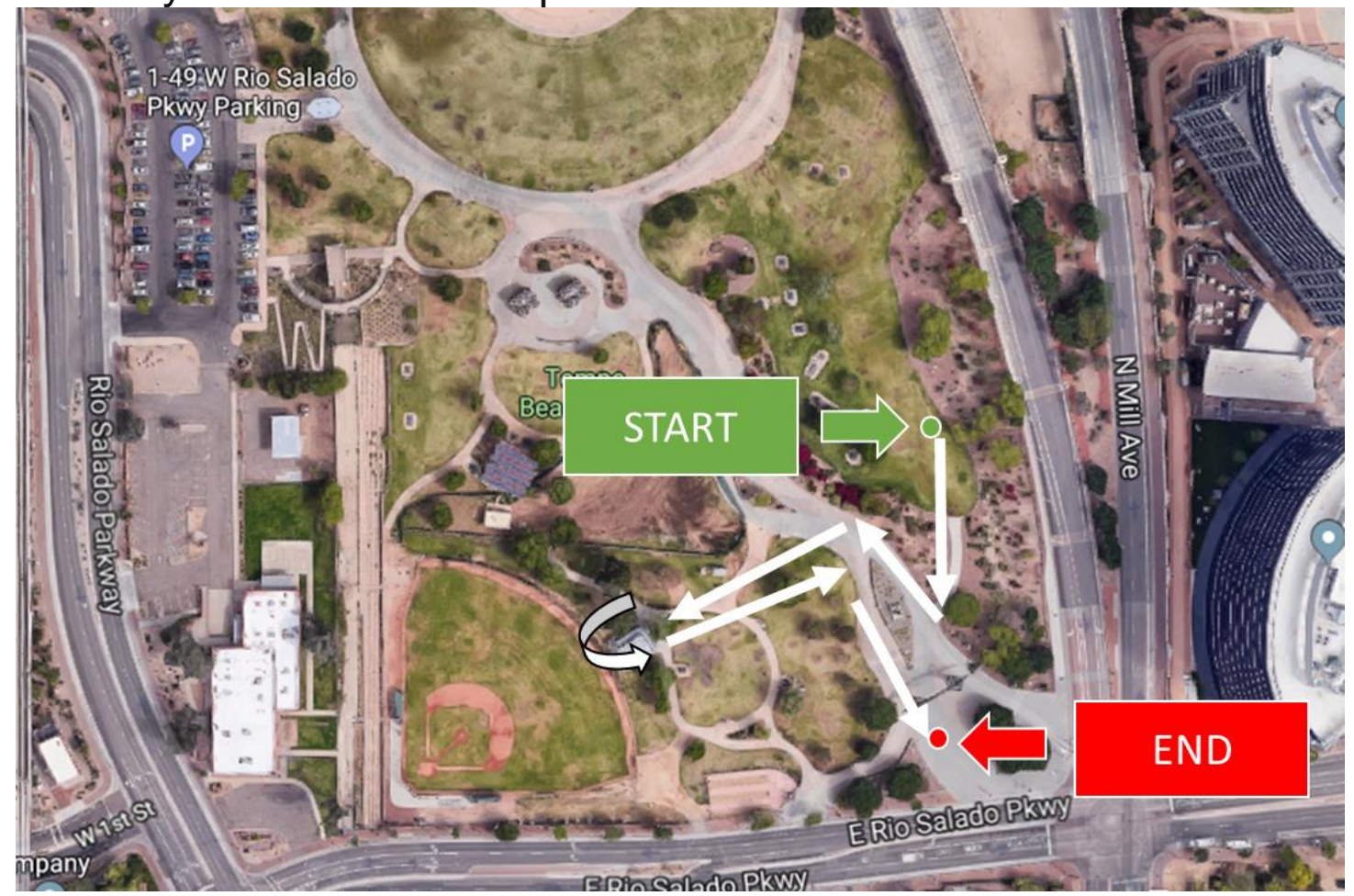


Remember: DO NOT include any notes about what people are doing in the spaces. Look just at fixed items in the environment, such as parts of buildings, equipment, and signs. Describe any items that you see in this location that could make any of the following groups feel unwelcome or excluded. Identify what you see, and tell us why you think it could be unwelcoming to any of the groups. Describe as many items as you can for each category. If there are no items relevant to that category, write "none".

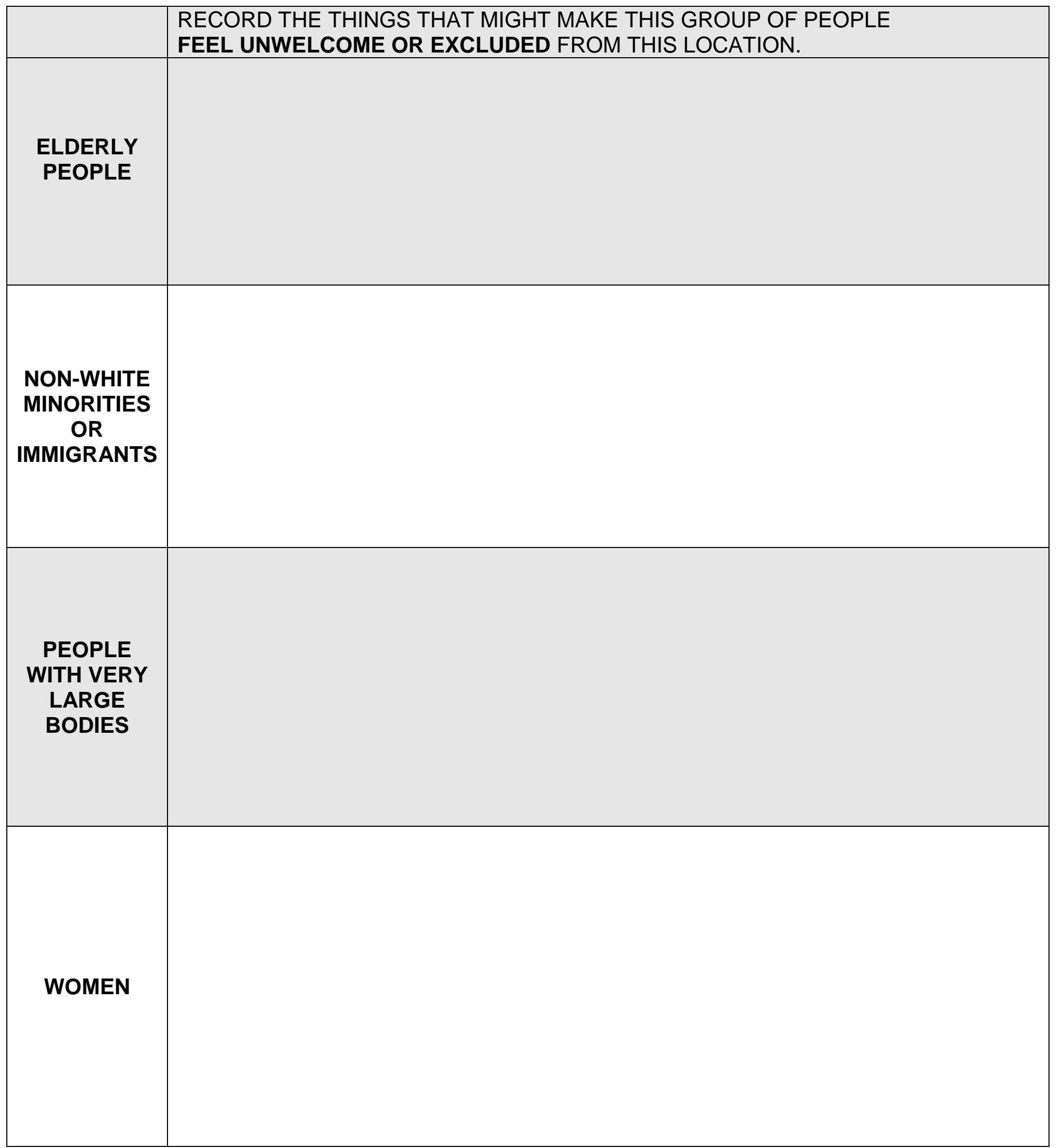




\section{LOCATION 4: Light rail station Mill and $3^{\text {rd }}$ street}

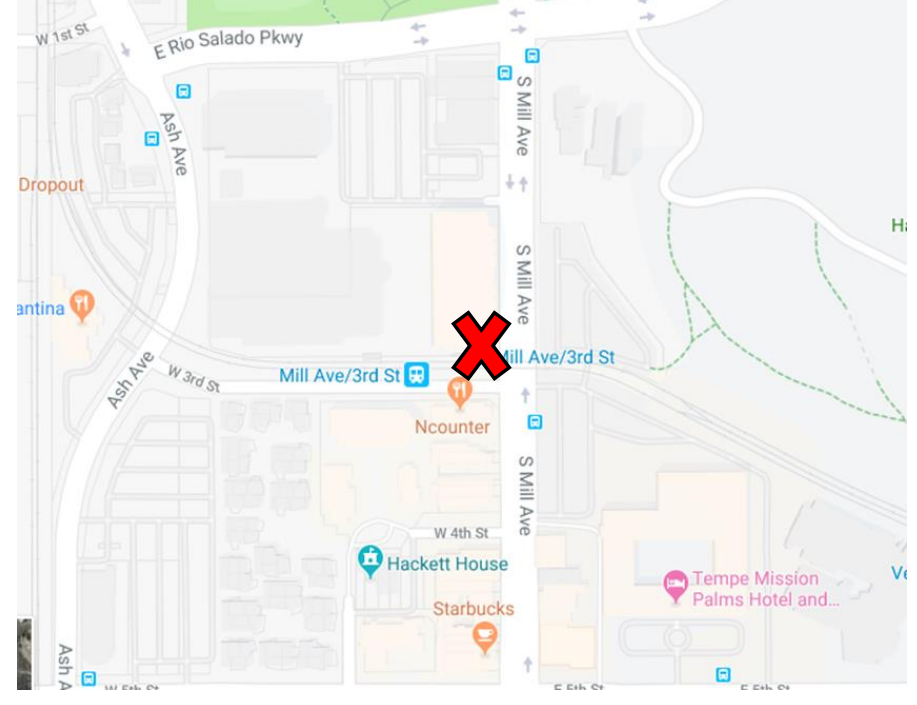

STARTING POINT: North West corner of Mill and Third street at entrance to light rail station.

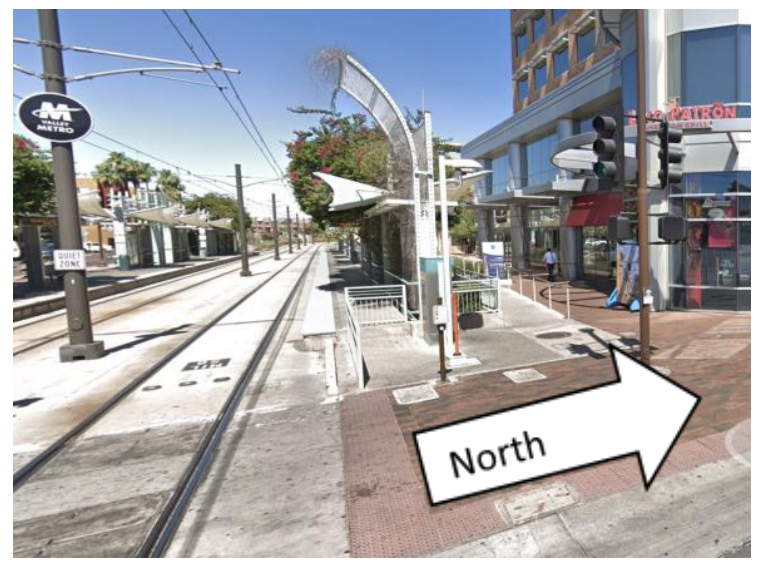

RECORDING INSTRUCTIONS: At the North West Corner of Mill and West $3^{\text {rd }}$ Street, walk West across the light rail platform on the back (north side) of the seating and screens. At end of light rail platform, turn around and walk back on the train (south) side of the North platform.

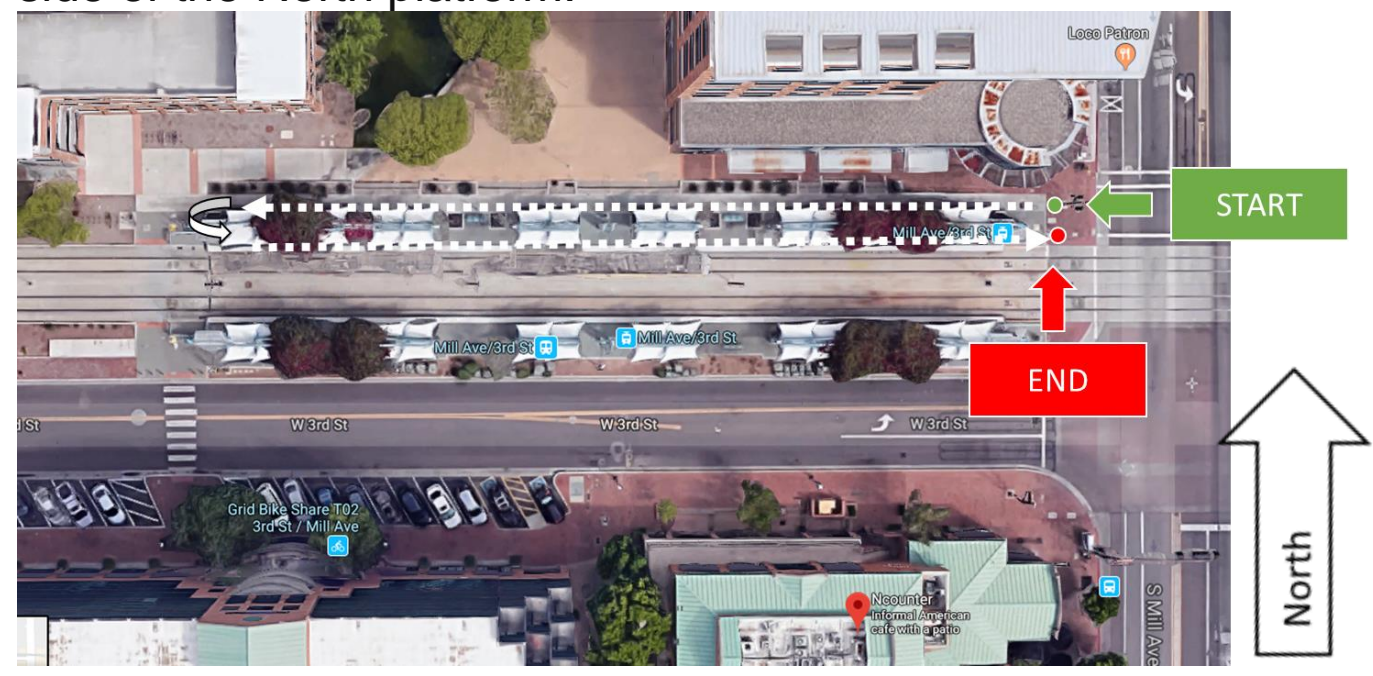


Remember: DO NOT include any notes about what people are doing in the spaces. Look just at fixed items in the environment, such as parts of buildings, equipment, and signs. Describe any items that you see in this location that could make any of the following groups feel unwelcome or excluded. Identify what you see, and tell us why you think it could be unwelcoming to any of the groups. Describe as many items as you can for each category. If there are no items relevant to that category, write "none".

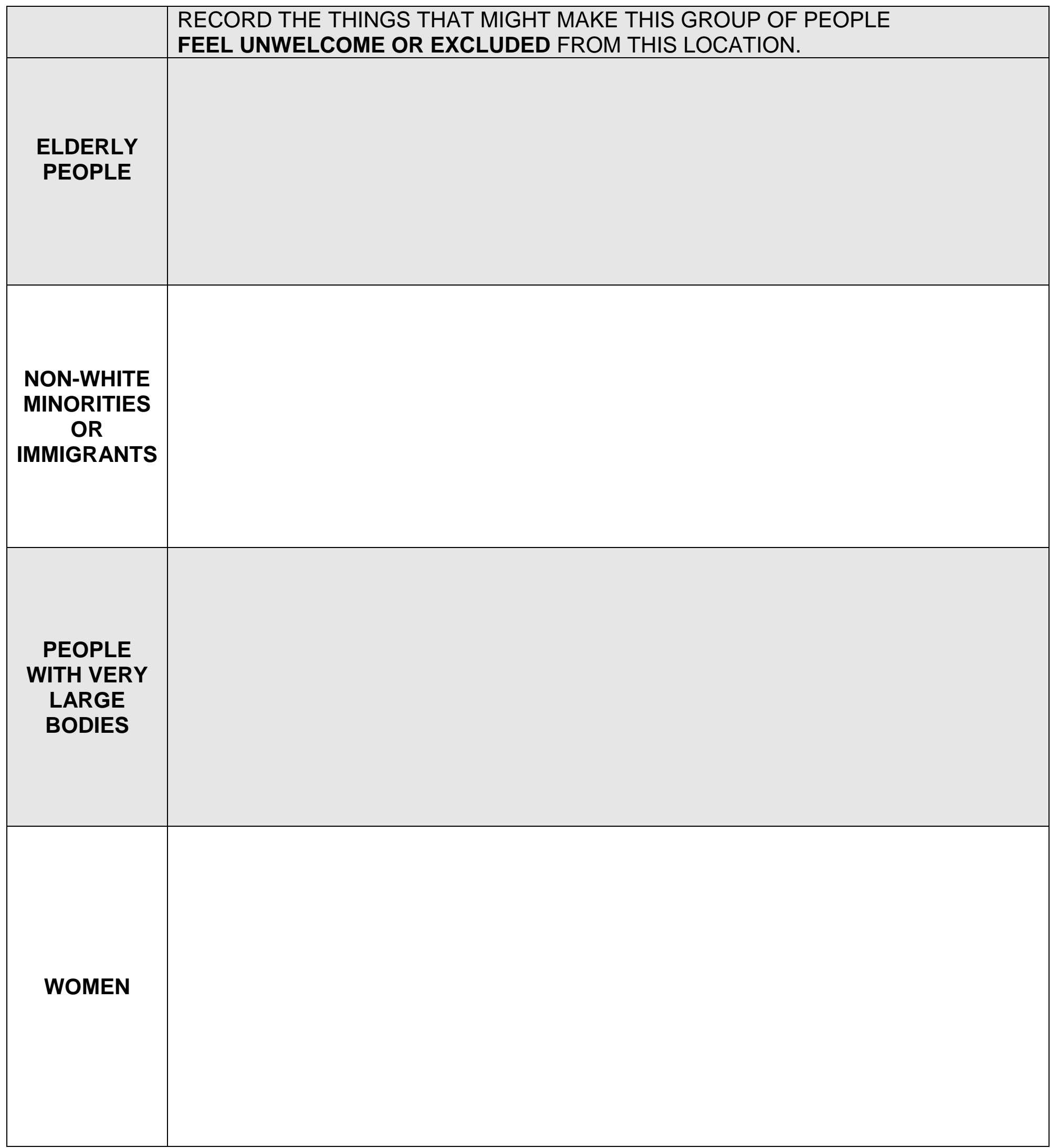


LOCATION 5: Starbucks ( $5^{\text {th }}$ Street and University, North West corner)

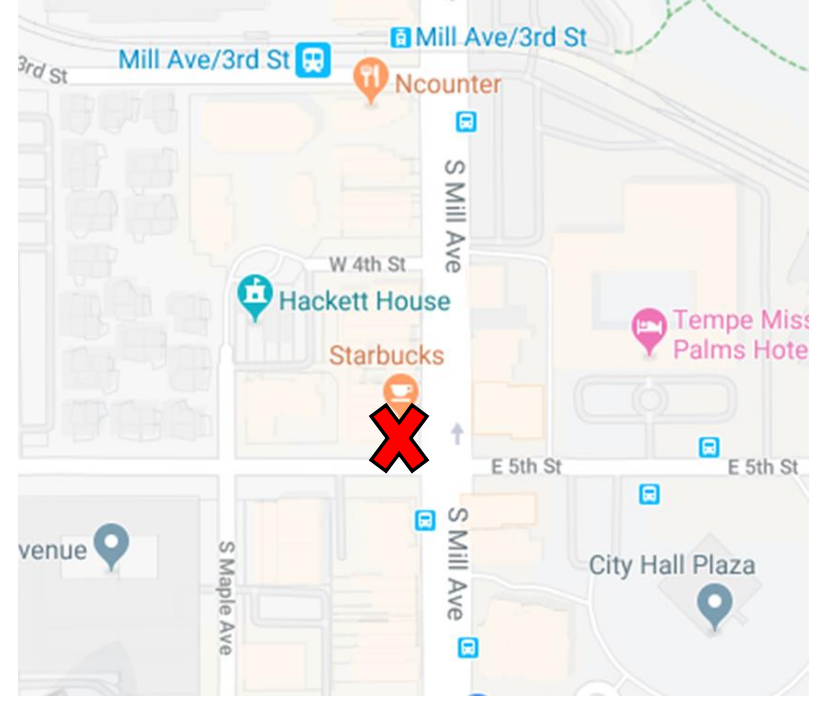

STARTING POINT: At Starbucks storefront on North West corner of $5^{\text {th }}$ and University

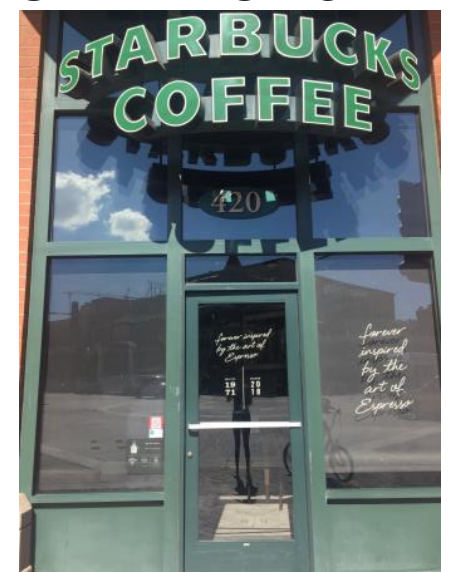

RECORDING INSTRUCTIONS: Walk inside. Walk to condiment stand. Face away from the condiment stand and observe the store.

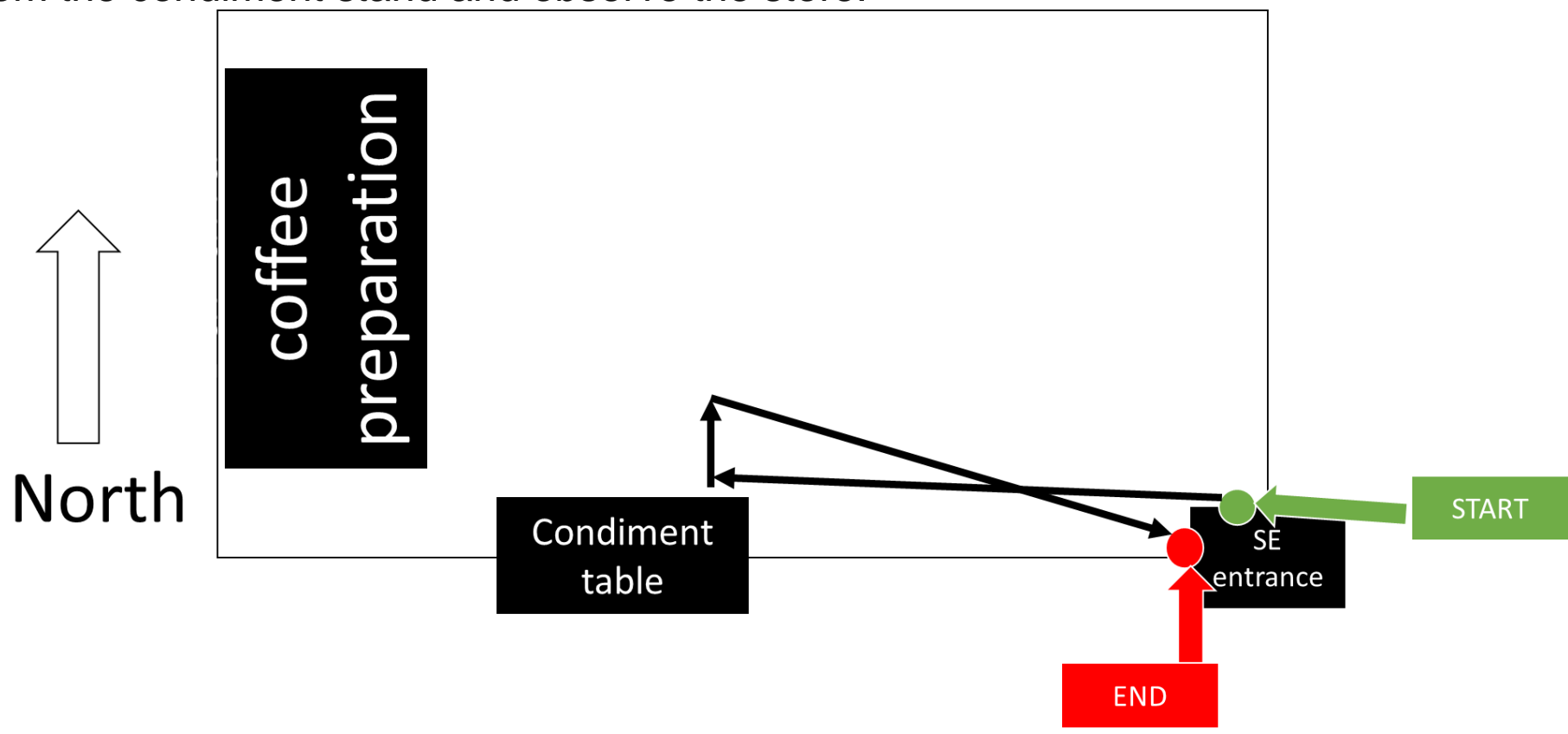


Remember: DO NOT include any notes about what people are doing in the spaces. Look just at fixed items in the environment, such as parts of buildings, equipment, and signs. Describe any items that you see in this location that could make any of the following groups feel unwelcome or excluded. Identify what you see, and tell us why you think it could be unwelcoming to any of the groups. Describe as many items as you can for each category. If there are no items relevant to that category, write "none".

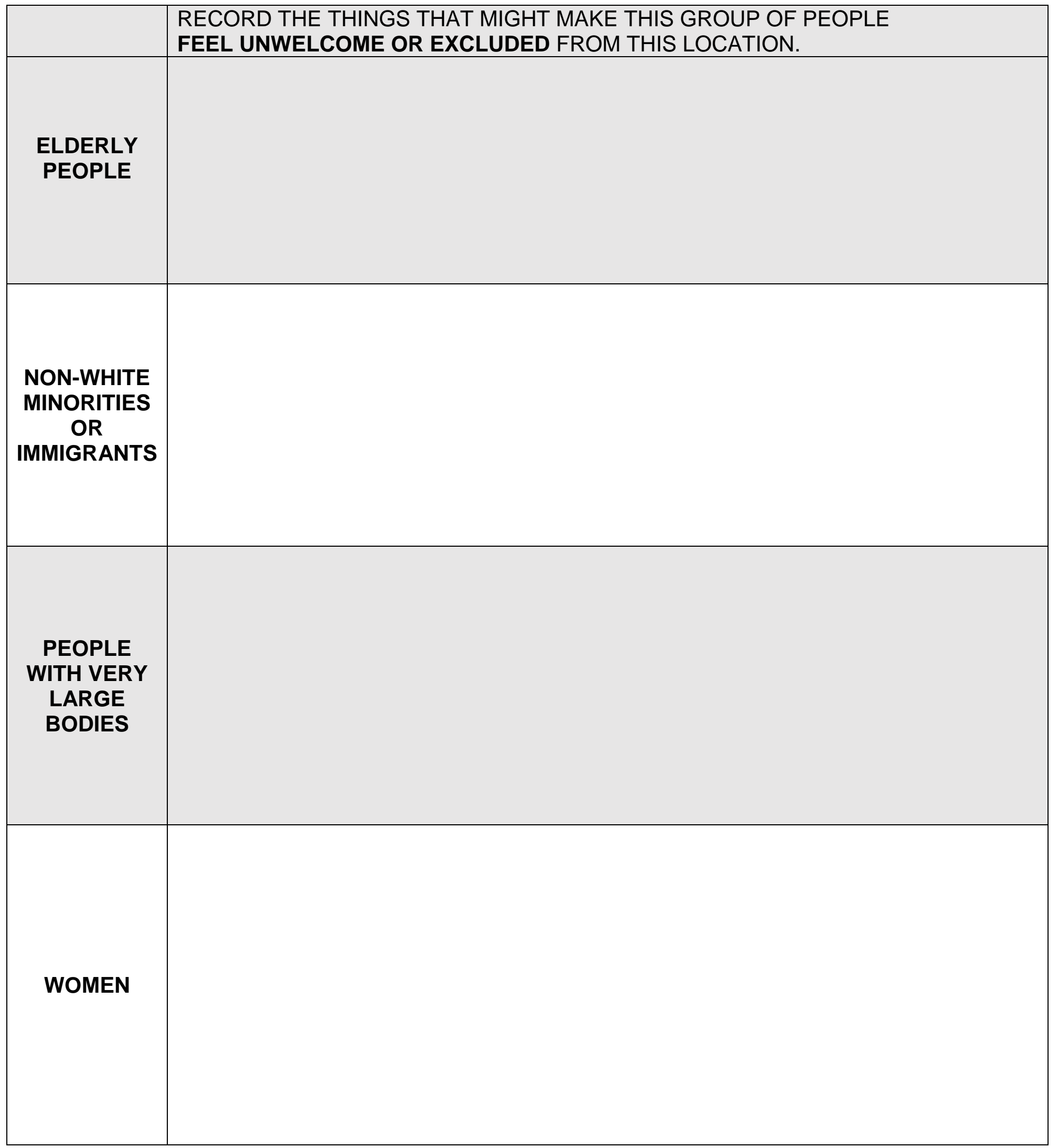




\section{LOCATION 6: Pitaya storefront}

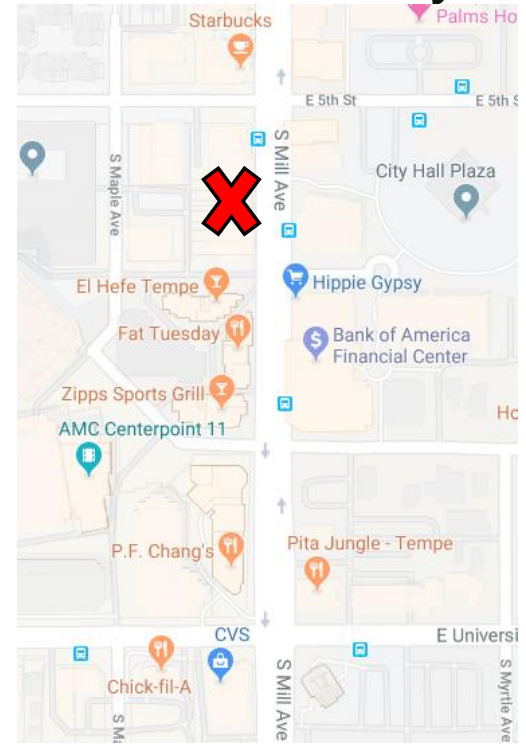

STARTING POINT: Pitaya clothing store at 524 S. Mill Avenue, South of the Post Office.

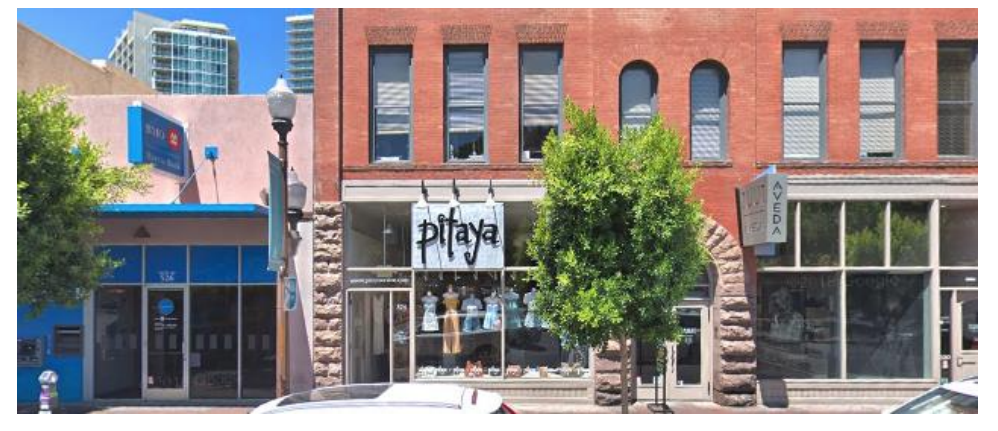

RECORDING INSTRUCTIONS: Observe through the storefront window.

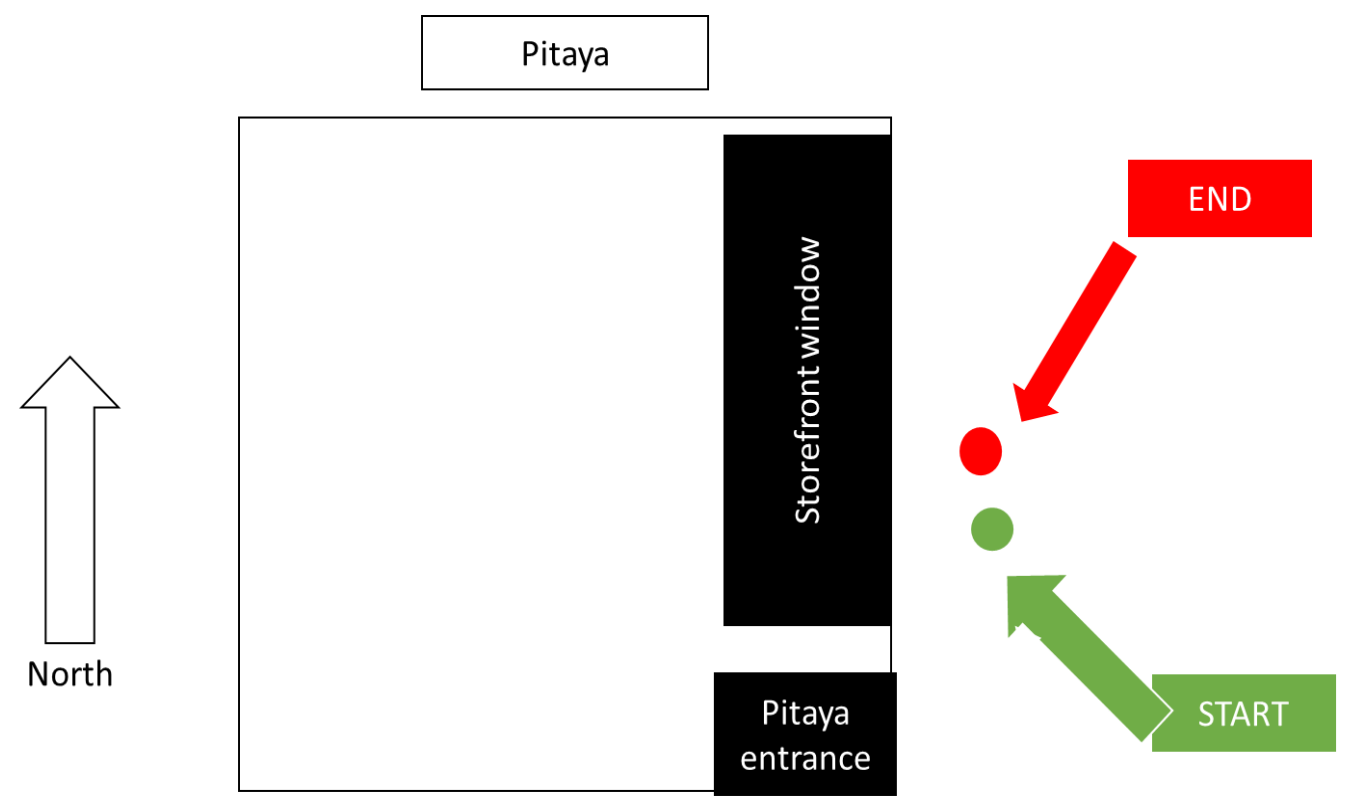


Remember: DO NOT include any notes about what people are doing in the spaces. Look just at fixed items in the environment, such as parts of buildings, equipment, and signs. Describe any items that you see in this location that could make any of the following groups feel unwelcome or excluded. Identify what you see, and tell us why you think it could be unwelcoming to any of the groups. Describe as many items as you can for each category. If there are no items relevant to that category, write "none".

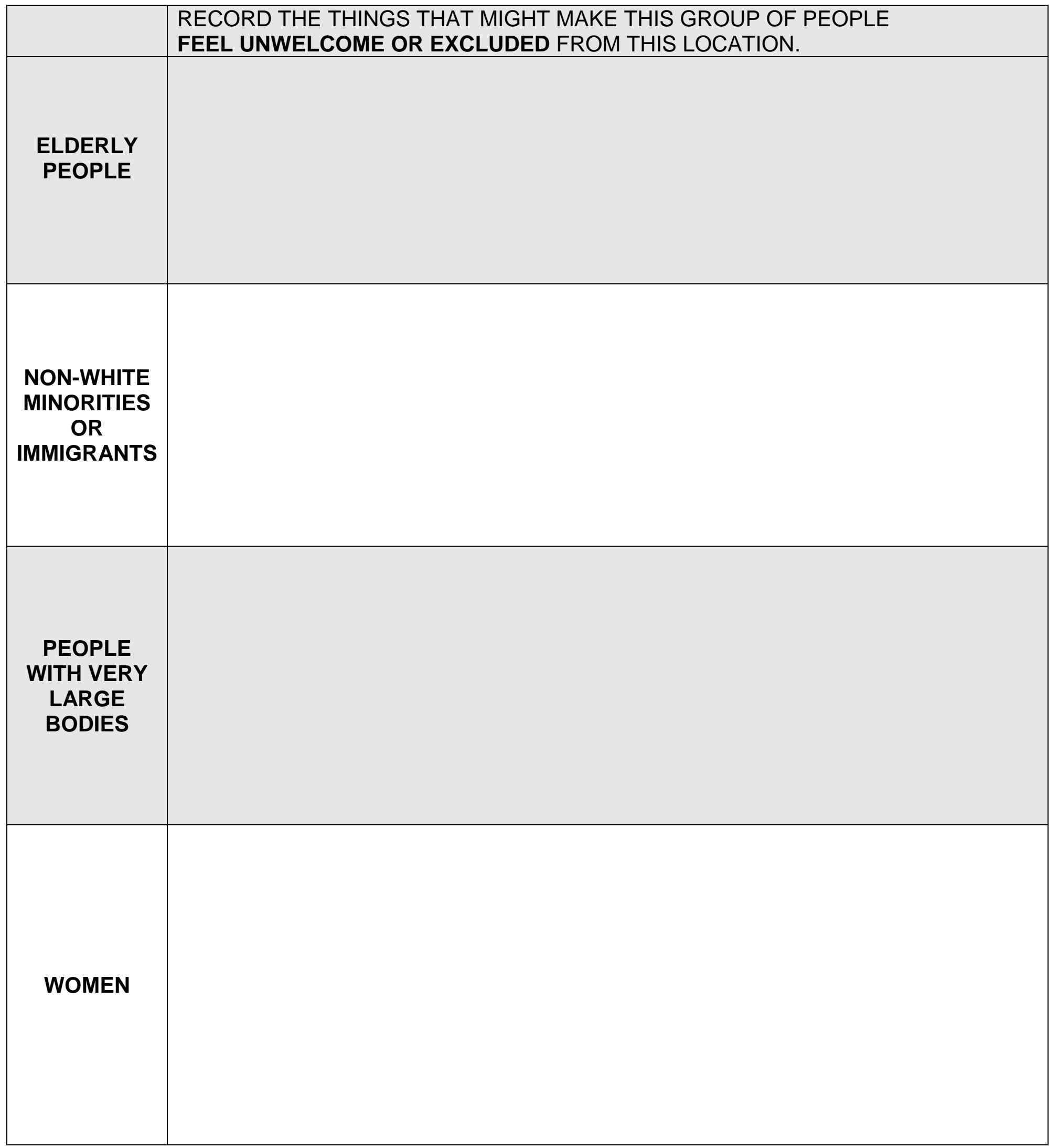




\section{LOCATION 7: CVS (802 South Mill Avenue)}

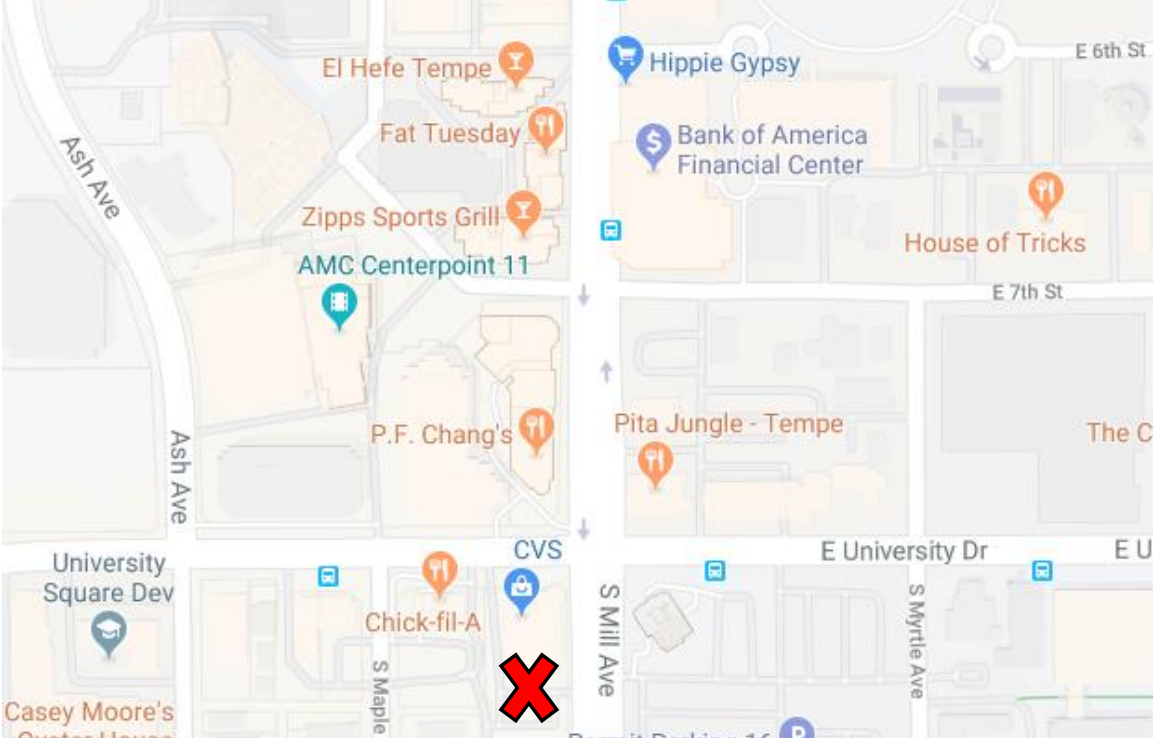

STARTING POINT: South entrance of CVS (802 South Mill Avenue, SW corner of Mill Avenue and University Drive).

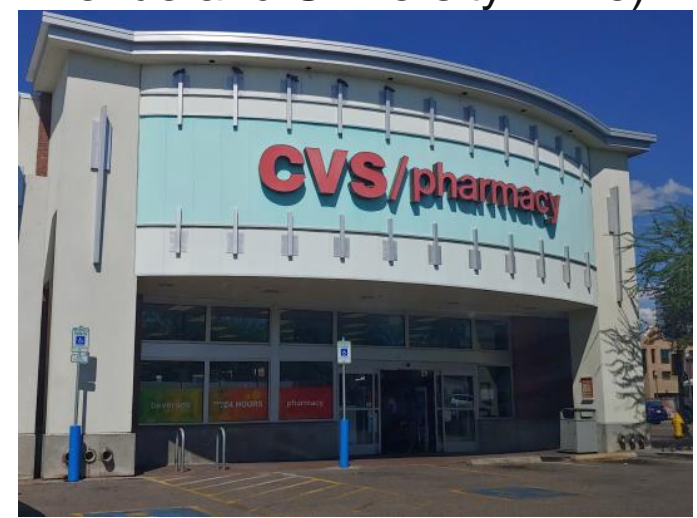

RECORDING INSTRUCTIONS: Enter the store. Turn left and walk to the pharmacy waiting area. Turn right and walk through the refrigeration section to the other (North) side of the store. Turn right and walk to the self-checkout machines, turn right and walk down the make-up isle to the other (South) side of the store. Exit the store.

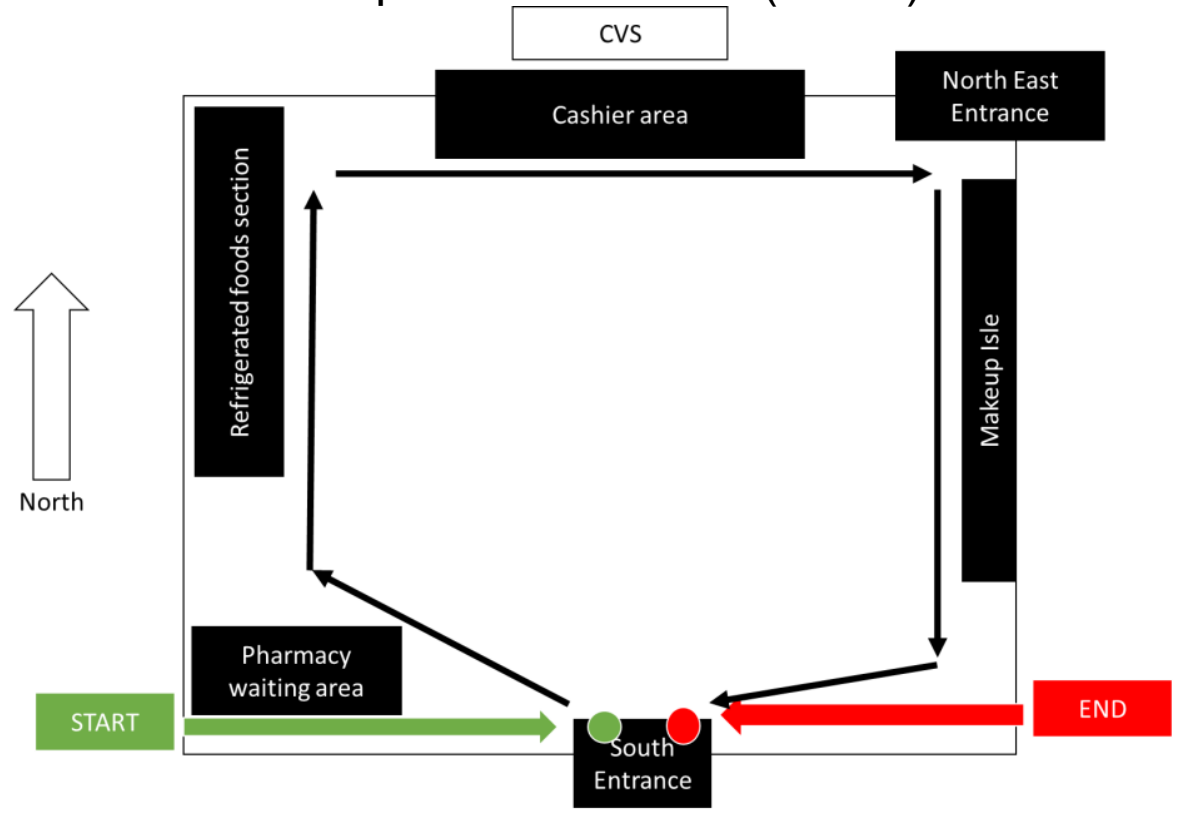


Remember: DO NOT include any notes about what people are doing in the spaces. Look just at fixed items in the environment, such as parts of buildings, equipment, and signs. Describe any items that you see in this location that could make any of the following groups feel unwelcome or excluded. Identify what you see, and tell us why you think it could be unwelcoming to any of the groups. Describe as many items as you can for each category. If there are no items relevant to that category, write "none".

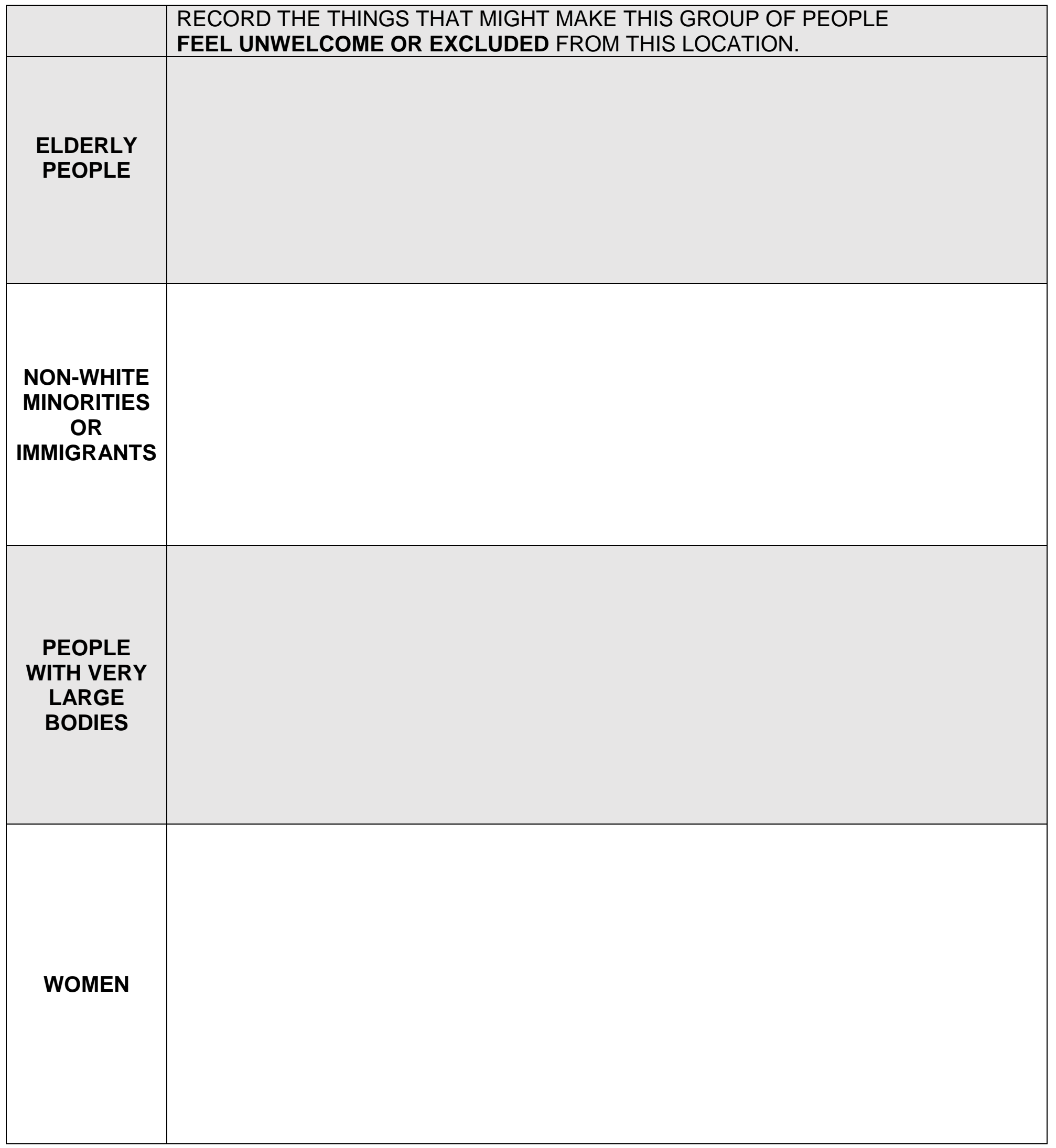


LOCATION 8: Brickyard parking structure ( $7^{\text {th }}$ Street and Mill Avenue)

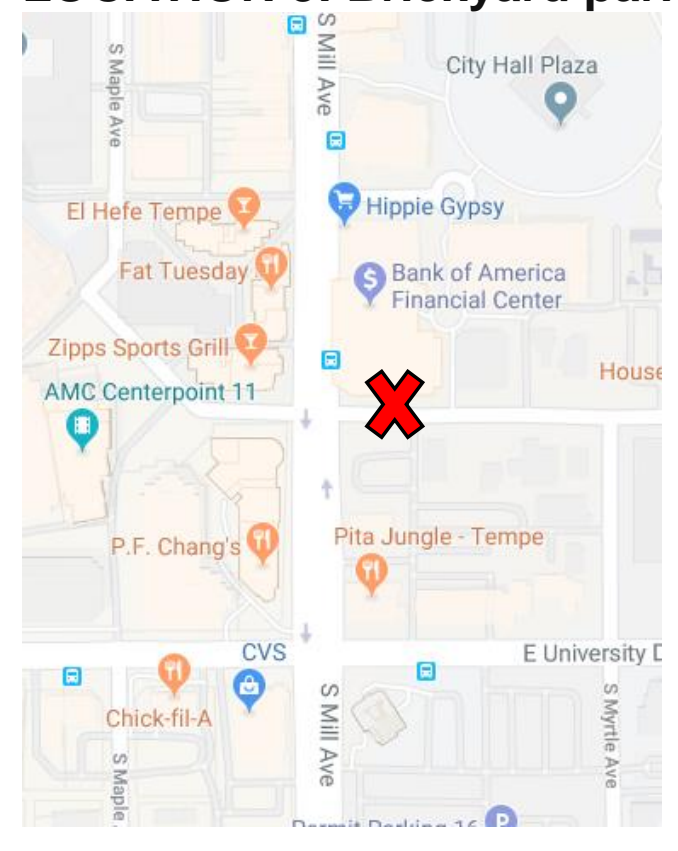

STARTING POINT: $7^{\text {th }}$ Street stairwell entrance to the Brickyard parking structure.

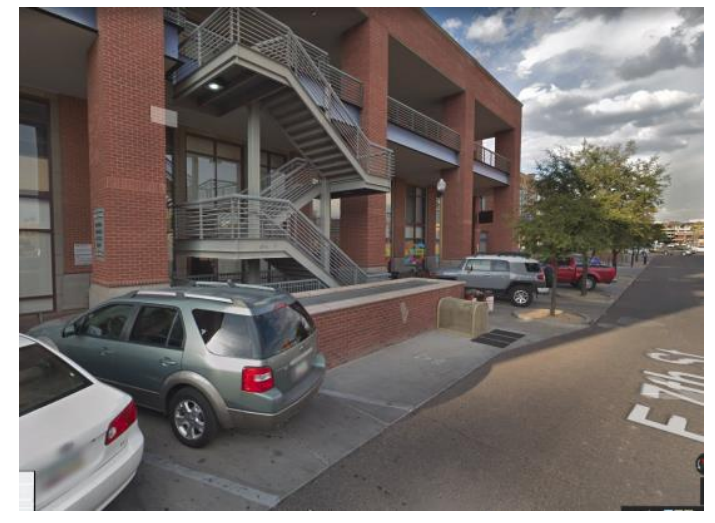

\section{RECORDING INSTRUCTIONS:}

Walk down stairs to first garage level. Walk north across parking lot to the elevators/ Enter an elevator and take it to the ground level.

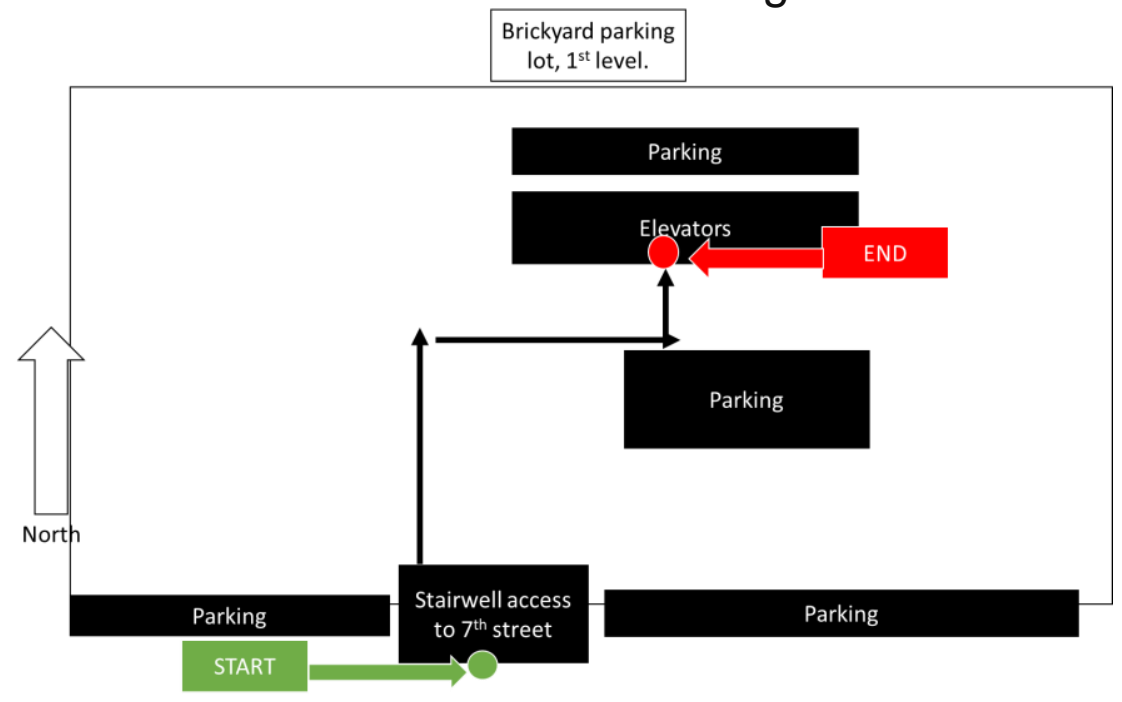


Remember: DO NOT include any notes about what people are doing in the spaces. Look just at fixed items in the environment, such as parts of buildings, equipment, and signs. Describe any items that you see in this location that could make any of the following groups feel unwelcome or excluded. Identify what you see, and tell us why you think it could be unwelcoming to any of the groups. Describe as many items as you can for each category. If there are no items relevant to that category, write "none".

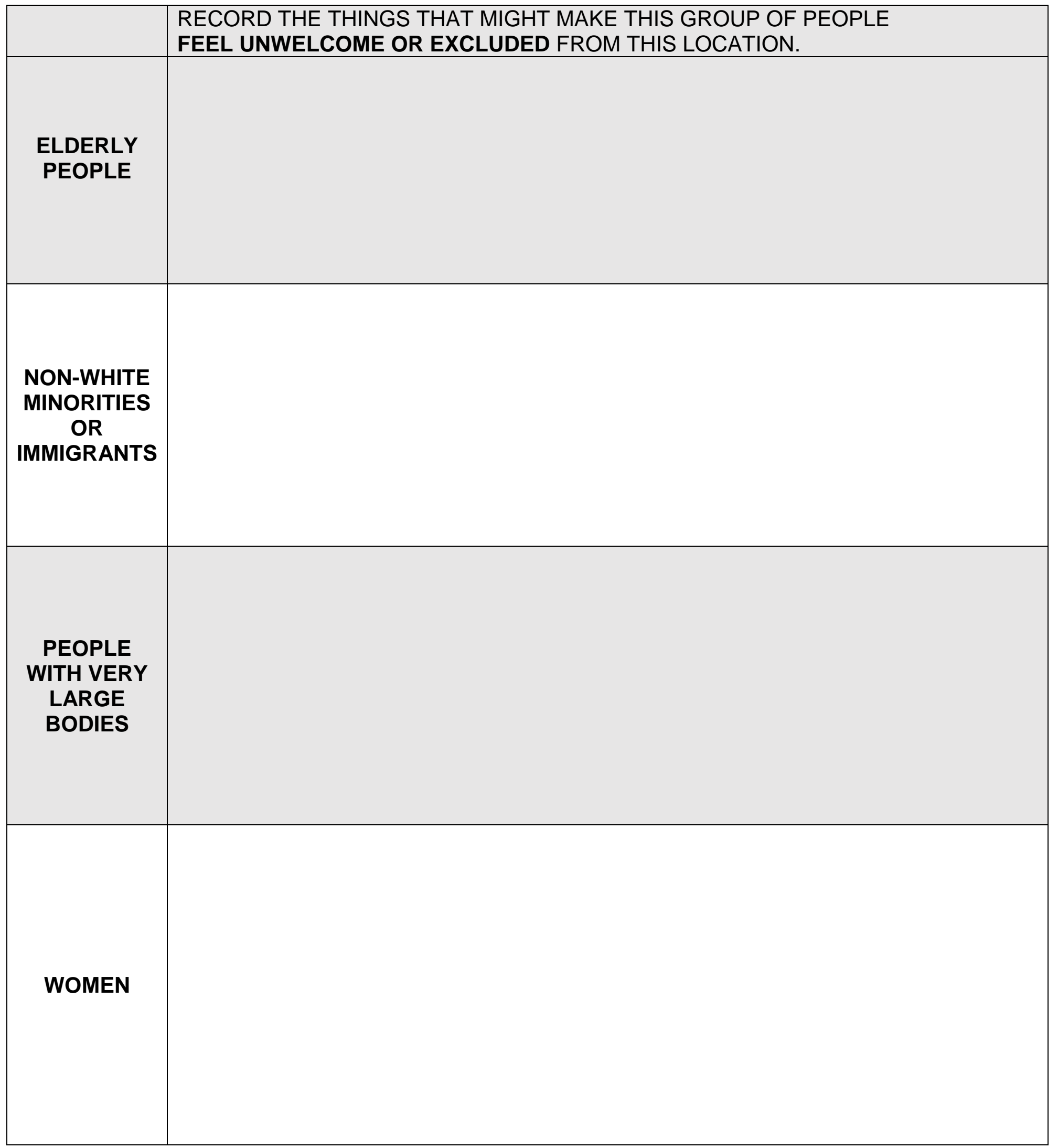


LOCATION 9: Tempe Mission Palms lobby (3685, 60 E. $5^{\text {th }}$ St. North Entrance) Mill Ave/3rd St

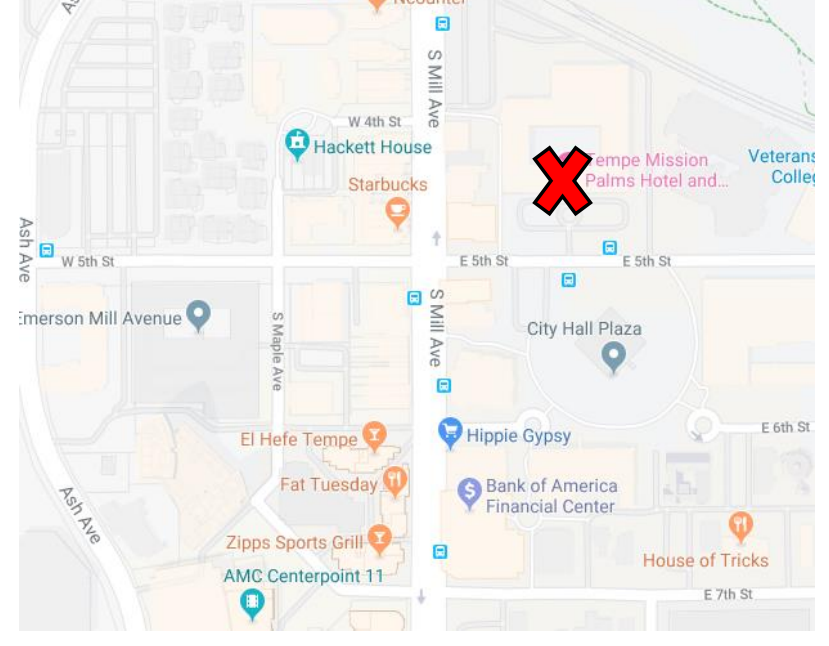

STARTING POINT: $5^{\text {th }}$ Street entrance to the lobby of Tempe Mission Palms.

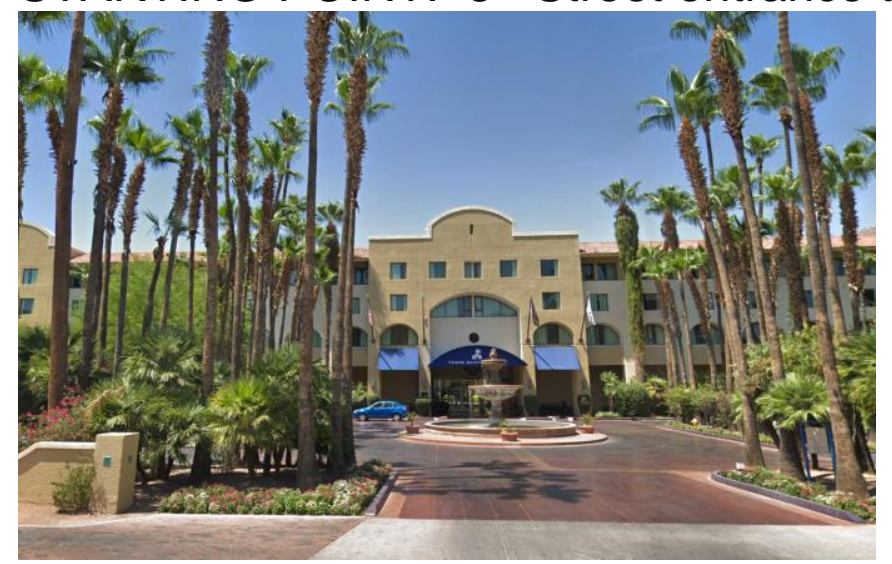

RECORDING INSTRUCTIONS:

Enter Tempe Mission Palms lobby. Walk to the center of the lobby and make observations. Then, exit through same entrance.

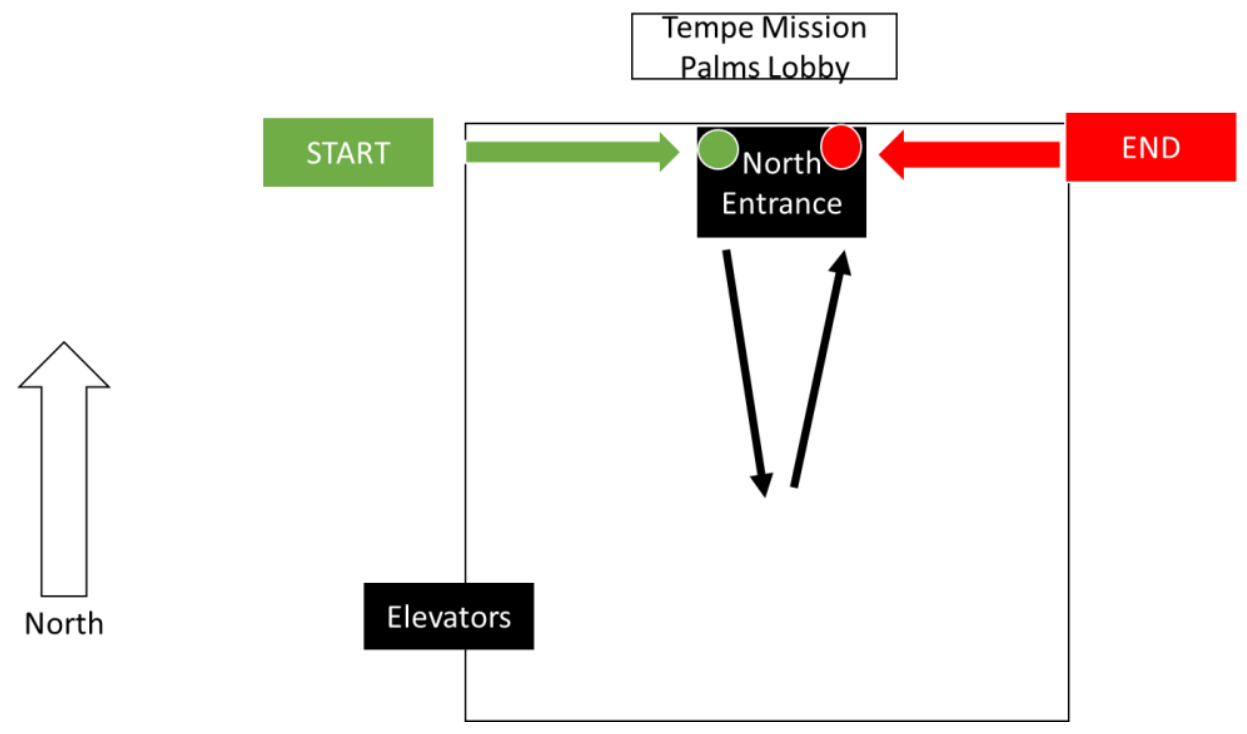


Remember: DO NOT include any notes about what people are doing in the spaces. Look just at fixed items in the environment, such as parts of buildings, equipment, and signs. Describe any items that you see in this location that could make any of the following groups feel unwelcome or excluded. Identify what you see, and tell us why you think it could be unwelcoming to any of the groups. Describe as many items as you can for each category. If there are no items relevant to that category, write "none".

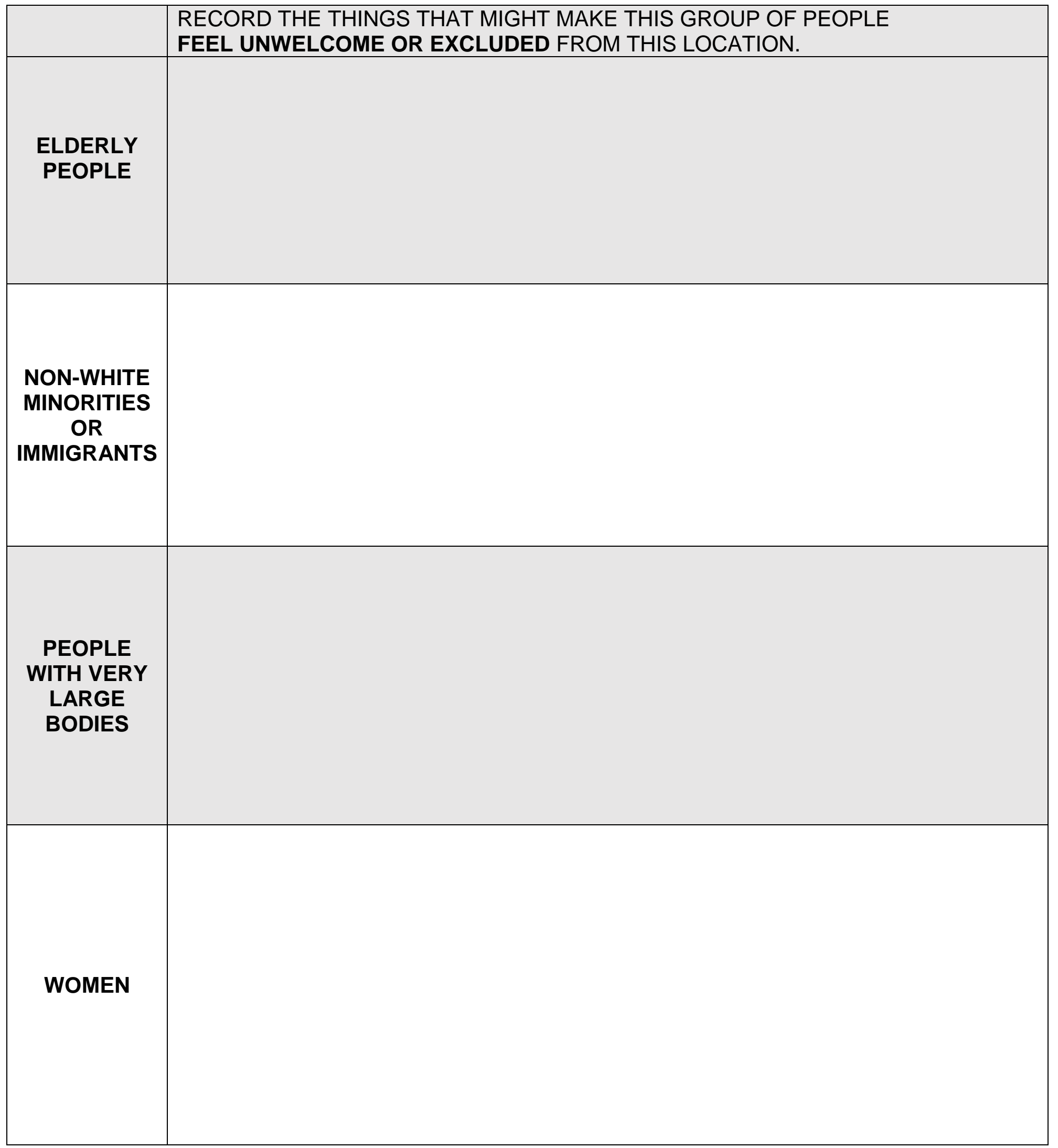


RECORD ADDITIONAL NOTES FOR THE TEAM HERE. Did you have any issues, concerns, or advice for us?

Field checked by: Issues:

Date:

Data entry by:

Date:

Issues: 


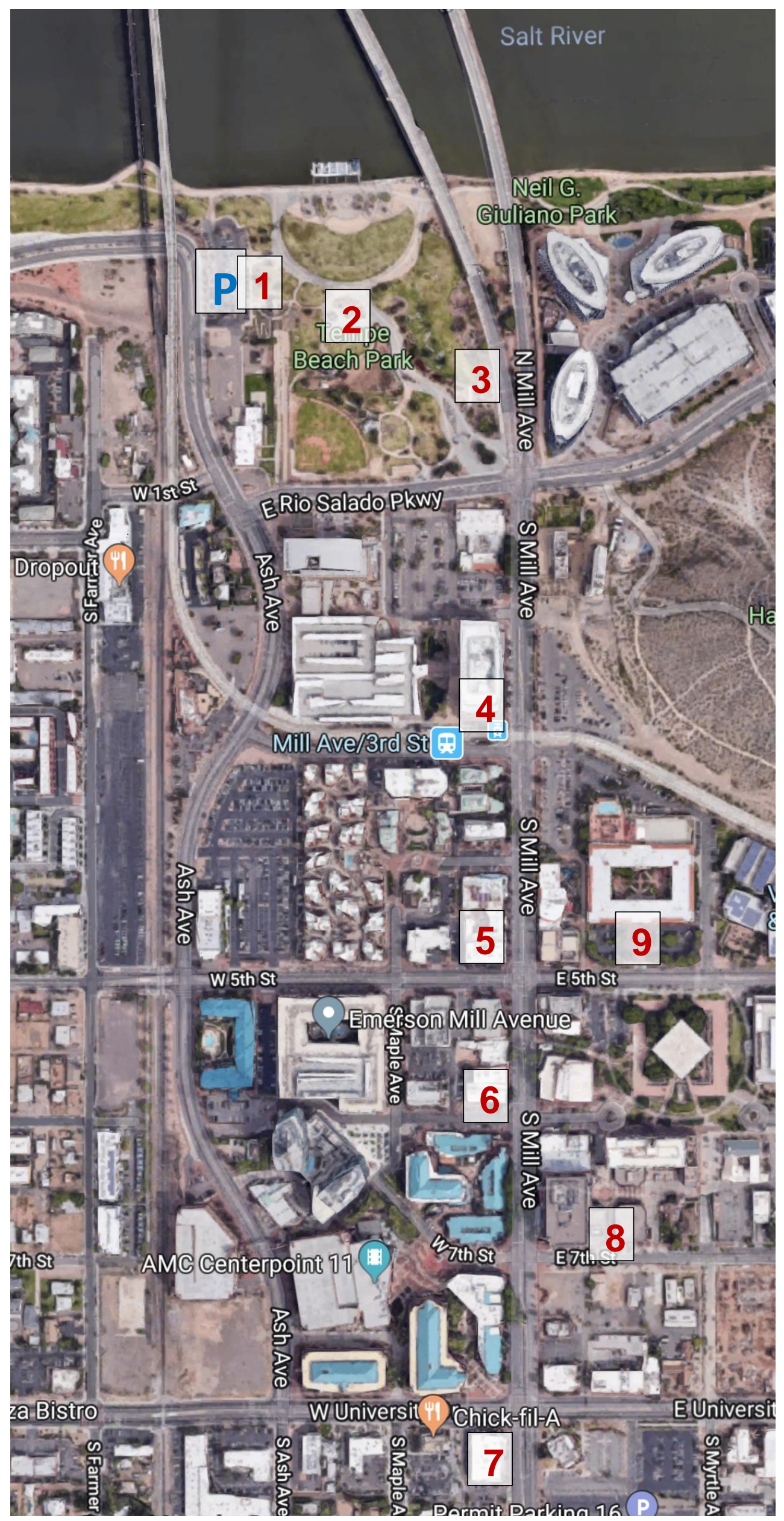

